\title{
Leituras e leitores de Richard Morse: a trajetória de um livro sobre a formação da metrópole paulista'
}

\begin{abstract}
Ana Claudia Veiga de Castro ${ }^{2}$
RESUMO: O livro De comunidade à metrópole: a biografia de São Paulo, publicado em 1954 e reeditado em 1970 com um novo título, Formação histórica de São Paulo: de comunidade à metrópole, foi escrito por um jovem norte-americano encantado com a América Latina, tendo sido inicialmente apresentado como tese de doutorado na Universidade de Columbia, em 1952. Desde então, essa obra de Richard Morse (1922-2001) percorreu um longo caminho, sendo hoje considerada "um clássico" sobre a evolução urbana da capital paulista. Retoma-se sinteticamente aqui a recepção da publicação, recuperando leitores e leituras que acabaram por garantir ao livro de Morse esse lugar na historiografia paulistana e brasileira. Busca-se, desse modo, traçar um paralelo entra a trajetória do livro e a de seu autor - que de jovem investigador em Columbia torna-se professor de História da América Latina na Universidade de Yale - para discutir o sentido do livro na historiografia e na própria interpretação que o livro fundaria sobre a cidade de São Paulo.

PALAVRAS-CHAVE: Richard Morse. Cidade. História urbana. Historiografia. São Paulo.

ABSTRACT: De comunidade à metrópole: a biografia de São Paulo, was first published in 1954 and then re published in 1970 as Formação histórica de São Paulo: de comunidade à metrópole. Written by a young US researcher fascinated by Latin America, this material was originally submitted as his PhD thesis at Columbia University in 1952. Since then, Richard Morse's (1922-2001) work has come a long way and is now considered a primary reference in the history of urban development of São Paulo. This article briefly recovers the reader's response when Morse's research was first published, and how it ensured the book's importance in the Brazilian historiography. The aim is to draw a parallel trajectory of the book and its author - the young researcher at Columbia who became a professor of Latin American History at Yale - and to discuss the meanings regarding its importance in São Paulo's historiography as well as its contribution to a better understanding of the city.

KEYWORDS: Richard Morse. City. Urban history. Historiography. São Paulo.
\end{abstract}

1. Este artigo apresenta resultados parciais da tese de doutoramento denominada Um americano na metrópole [latino-americana]. Richard Morse e a bistória cultural urbana de São Paulo, 19471970, defendida na FAUUSP e financiada pela FAPESP

2. Arquiteta e urbanista, docente da Escola da Cidade, Faculdade de Arquitetura e Urbanismo. Mestre (2005) e doutora (2013) pela Faculdade de Arquitetura e Urbanismo da Universidade de São Paulo. E-mail <anacvcastro@gmail.com>. 
3. Cf. Richard Morse (1970, p.44).

4. Cf. Richard Morse (1970, p.255).

5. Cf. Richard Morse (1970, p.294).

6. Como se sabe, a partir do governo Roosevelt (19331954), os norte-americanos agiram intensamente para estreitar os laços entre os países do continente, incentivando a aproximação dos Estados Unidos aos vizinhos do sul, no que foi denominado política da Boa Vizinhança. Coordenada em parte por Nelson Rockefeller (1908-1979), essa política teve desdobramentos importantes nas universidades norteamericanas mesmo depois da Guerra, como o surgimento de programas que impulsionavam os estudos latino-americanos ao enviar estudantes para os mais variados países do continente numa espécie de cruzada acadêmica, ação que se acentuaria ainda mais com a promulgação do National Defense Education Act em 1958; a esse respeito ver entre outros Paulo Roberto R. de Almeida (2001). Deste modo, as decisões e escolhas de Morse extrapolam os desejos e as inclinações pessoais ao se inscreverem neste contexto propício. Não é minha intenção neste artigo entretanto desenvolver este aspecto, vale apenas notar que o historiador, assim como outros pesquisadores durante aqueles anos, vem para São Paulo com uma bolsa do próprio Departamento de Estado norte-americano; ver José Carlos Sebe Bom Meihy (1990).

7. Perspectiva explorada em minha tese de doutorado; ver Ana Claudia Veiga de Castro (2013).
Após passar pouco mais de um ano em São Paulo reunindo material para sua pesquisa, o norte-americano Richard Morse (1922-200 1) publicou o livro que acabou se tornando um dos mais importantes trabalhos sobre a história da capital paulista: De comunidade à metrópole: biografia de São Paulo, mais conhecido talvez como Formação histórica de São Paulo: de comunidade à metrópole, tífulo de sua segunda edição no Brasil. Nesse ensaio, Morse repassava a história de São Paulo ao longo dos séculos desde a sua fundação, mobilizando fontes as mais diversas, de documentos oficiais aos acervos privados, da literatura aos trabalhos científicos, incluindo cantigas e pregões, cartas, notícias e anúncios de jornal, e tudo mais que ao ser reordenado e analisado pudesse recompor a vida na cidade:

Na metrópole caleidoscópica de hoje ninguém toma conhecimento direto do fluxo de produtos e de pessoas que a todo instante entra e sai do centro. Mas, em tempos mais antigos, qualquer vadio sabia quando entrava na cidade pela Rua do Piques um carregamento de açúcar vindo de ltu em mulas. Mesmo a visita de um estrangeiro era publicamente registrada: a chegada de Mawe em 1807 atraiu uma chusma de crianças, que contavam seus dedos para ver se ele tinha o mesmo número que elas ${ }^{3}$.

As técnicas italianas começaram a dominar a cidade durante as primeiras décadas de sua expansão e eram bem distintas daquelas dos pedreiros portugueses, que implantaram seu estilo no Rio, ao longo do litoral e em outras regiões. Os italianos preferiram, por exemplo, os alicerces de tijolo aos de pedra, e na carpintaria usavam pregos ao invés de parafusos, o que tinha o efeito de mudar as possibilidades estruturais de certas madeiras ${ }^{4}$.

Muitos grã-finos são parvenus desprovidos de raízes culturais, a gozarem lucros excessivos francamente onerados por impostos. Seu ritmo mais acelerado de vida fez com que um complexo norte-americano de martinis, clubes noturnos, Cadillacs e fins-de-semana esportivos substituísse as afetações francesas do passado recente ${ }^{5}$.

Tais trechos são alguns exemplos de como Richard Morse conseguiu dar vida à capital paulista, captando nuances da sua transformação ao longo dos séculos por meio de detalhes que às vezes poderiam parecer secundários, mas que em seu conjunto pretendiam compor um retrato do que teria levado a pequena vila de São Paulo de Piratininga ao posto de uma das mais importantes cidades latinoamericanas na década de 1950. Escrito inicialmente como tese de doutorado por um jovem norte-americano encantado com a América Latinab, seu texto acabou se tornando obra fundamental da historiografia paulista. Este artigo tem a intenção de lançar luz em alguns aspectos da publicação, contribuindo para o entendimento de como isso ocorreu. Sem tratar de maneira exaustiva da biografia do autor nem propor uma análise mais detida do texto ${ }^{7}$, pretende-se acompanhar a trajetória da sua publicação, retomando as diversas edições e recuperando leitores e leituras que deram à obra um lugar de destaque - como parte de um esforço maior de compreensão desse livro no campo da história urbana em São Paulo. 
Sendo editado pela primeira vez em 1954, na efeméride do IV Centenário de São Paulo, e reeditado dezesseis anos depois numa prestigiosa coleção que pretendia "explicar" o Brasil, pode-se facilmente constatar que ao longo das décadas a obra de Morse tornou-se leitura obrigatória àqueles que escreveram sobre São Paulo e suas transformações urbanas. Mas porque será que o livro alcançou esse status? Por apresentar uma versão da história da cidade que nos convence? Por reunir dados de artigos dispersos de historiadores de outros tempos e viajantes de muitas épocas que nos poupa de pesquisas mais aprofundadas? $\bigcirc$ que a faz, afinal, ter uma vida tão profícua e longeva? É certo que a maioria dos trabalhos científicos sobre São Paulo publicados após o aparecimento do livro de Morse abordam o período pós 1870, e que apenas mais recentemente o período colonial paulista começou a ganhar relevo entre as pesquisas acadêmicas ${ }^{8}$. Portanto, seu livro, que trata da passagem da vila à metrópole, com foco no desenvolvimento urbano do século XIX em diante, teria interesse privilegiado por seu próprio recorte cronológico, já que pode nos ajudar a compreender no geral o que os outros trabalhos buscaram tratar no específico. $\bigcirc$ que não se duvida é que a abordagem de Morse da cidade ainda cativa o leitor.

Não faz sentido discutir aqui todos os autores que tomaram o trabalho de Richard Morse sobre São Paulo como fonte, o que demandaria um esforço e um espaço que as intenções deste artigo não supõem. Mas interessa apontar que, apesar das diferenças de abordagens sobre a história de São Paulo em cada um dos autores, quase todos parecem incorporar os argumentos expostos pelo norteamericano, de modo a confirmar as suas próprias hipóteses ou a exemplificar situações que as corroborem ${ }^{9}$. Em raros momentos contesta-se, problematiza-se ou mesmo se contextualiza a história da cidade apresentada pelo historiador, naturalizando desse modo seus argumentos e análises ${ }^{10}$.

A obra, contudo, conheceu uma trajetória particular. Tida hoje como "um clássico" sobre São Paulo - a se levar em conta os comentários que aqui e ali foram feitos ao longo das últimas décadas -, ela percorreu um longo caminho desde sua primeira edição no Brasil. Vejamos alguns destes comentários, tecidos em meio a depoimentos ou homenagens sobre o autor, sobretudo nas últimas duas décadas. Para Antonio Candido, seria um "livro forte e pessoal, talvez a melhor monografia até hoje escrita sobre a cidade"11; segundo Carlos Guilherme Mota, "seu primeiro livro tornou-se um clássico sobre São Paulo"12. Também já se disse que "o trabalho de Richard Morse sobre a evolução da cidade de São Paulo "ainda hoje [é] utilizado com interesse"13; que "o livro, que começa a circular em 1970, é referência obrigatória para os estudiosos das cidades em geral, e uma das grandes monografias a que os paulistanos fizeram jus (...)"14; que seria "o estudo mais laborioso e metódico sobre o tema, no qual, sem prejuízo de seu propósito rigorosamente científico, a capital dos paulistas não é reduzida a insipido objeto de ciência"15; ou chamado por um historiador mexicano de "notável (...) estudo histórico"16.

Resultado da tese de doutorado São Paulo. City under the empire $11822-$ 1889), que Richard Morse defendeu na Universidade de Columbia em 1952 sob
8. Como mostram os diversos artigos organizados por Maria Lúcia Perrone Passos (1992), que passam pelas humanidades: história, sociologia, antropologia, economia, geografia e urbanismo, apresentando uma revisão bibliográfica sobre São Paulo em cada um deles.

9. Apenas a leitura dos títulos já mostra o amplo espectro de autores $\mathrm{e}$ abordagens que vêm recorrendo ao livro de Morse: Warren Dean, $A$ industrialização de São Paulo (1971); Wilson Cano, Raízes da concentração industrial em São Paulo (1977); Benedito Lima de Toledo, São Paulo: três cidades em um século (1981); Joseph Love, $A$ Locomotiva: São Paulo na federação brasileira (1982); Nicolau Sevcenko, Orfeu extático na metrópole (1992); Lilia Schwarcz, $O$ espetáculo das raças (1993); Maria Cecília Naclério Homem, $O$ palacete paulistano (1996); Raquel Rolnik, A cidade e a lei (1997); Emilia Viotti da Costa, Da monarquia a República (1998); Hugo Segawa, Prelúdio da metrópole (2000); Heitor Frugoli, Centralidade em São Paulo (2000); Sarah Feldman, Planejamento $e$ zoneamento (2005); Maria Luiza de Oliveira, Entre a casa e o armazém (2005). E até mesmo um trabalho de historiografia como o de Silvio Luiz Lofego, Memória de uma metrópole: São Paulo na obra de Ernani da Silva Bruno (2001).

10. Algumas exceções, entretanto, devem ser notadas: Ilana Blaj, ao recuperar toda a historiografia paulista referente ao período colonial, discute brevemente algumas das afirmações de Morse (2002, p.69). Mais recentemente, Amílcar Torrão Filho (2010), toma Morse como parte de uma 
abordagem historiográfica, pensando na cidade do século XVIII. Paulo Cesar Garcez Marins, num trabalho sobre os Campos Elísios (2011, p. 209-244), também se anima a ler Morse, entre outros autores, buscando complexificar as versões da história da cidade.

11. Cf. Antonio Candido (1992, p.7), grifos meus.

12. Cf. Carlos Guilherme Mota (1992, p. 14), grifos meus.

13. Cf. Nestor Goulart Reis Filho (1992, p.40), grifos meus.

14. Cf. Maria Alice Rezende de Carvalho (1994, p.105), grifos meus.

15. Cf. Gilberto de Mello Kujawski (1988, p. 10), grifos meus.

16. Cf. Maurício Tenório Trillo (1989, p.104), grifos meus. Para uma avaliação da importância do livro no contexto latino-americano, ver Adrián Gorelik (2007).

17. Cientista social e historiador, PhD em economia, autor de The Mexican Agrarian Revolution (1929); Slave and Citizen (1947); Mexico: the Struggle for Peace and Bread (1950); A Philosophy of Labor (1951) e Ten Keys to Latin America (1962), entre outros.

18. Que resultaram no capítulo A metrópole moderna acrescentado na primeira edição de 1954 , cujos argumentos podem ser lidos nos artigos publicados nos anos anteriores, notadamente: "Brazilian Modernism" (The Hudson Review, 1950), "Sao Paulo in the 19th Century: Economic Roots of the Metropolis" (Inter-American Economic Affairs, 1951); "The Negro in Sao Paulo, a orientação do antropólogo Frank Tannenbaum (1893-1969)17, acrescido de partes da investigação feita no Brasil entre os anos de 1947 e 1948 mas que não

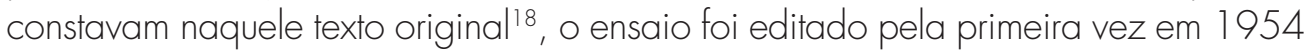
pelo Serviço de Publicações da Comissão do IV Centenário da Fundação de São Paulo, como parte da Biblioteca do IV Centenário. $\bigcirc$ livro se organizava em uma Introdução, que recuperava brevemente o passado colonial da cidade, e quatro capítulos que pretendiam dar conta das fases de desenvolvimento da capital paulista dali em diante: Colonialismo e novos estimulantes, tratando dos anos imediatamente anteriores e imediatamente posteriores à Independência; Surge a cidade-mente, buscando reconstruir o período anterior à economia cafeeira; Surge a cidadeorganismo, momento em que a cidade vivencia o auge daquela economia e todas as suas implicações no meio urbano e, por fim, A metrópole moderna, discutindo os atributos da metropolização nas primeiras décadas do século XX, estendendo eventualmente os comentários até a década de 195019.

Ainda que não tivesse sido elaborada com o objetivo de fazer parte das comemorações do aniversário da cidade, aproveitava-se a efeméride para que a tese fosse traduzida e chegasse às livrarias. Desse modo, a obra aparecia num momento de afirmação da identidade paulista, no qual a história pregressa era mobilizada - sobretudo nas ações oficiais ${ }^{20}$ - para dar lastro às ações do presente, ao lado de outras obras sobre São Paulo especialmente encomendadas ou organizadas para a ocasião. Entre elas constavam o Dicionário de Bandeirantes e Sertanistas do Brasil (1953) de Francisco de Assis Carvalho Franco; o Dicionário de Autores Paulistas (1954) de Luís Correia de Mello; a Bibliografia Crítica da Etnologia Brasileira (1954) de Herbert Baldus; a edição das Cartas dos Primeiros Jesuítas do Brasil e o volume de Poesias de José de Anchieta; e ainda São Paulo Antigo: Plantas Diversas da Cidade, todas editadas pelo mesmo Serviço de Comemorações Culturais da Comissão, formando uma espécie de coleção ${ }^{21}$. Também o livro coletivo organizado por Affonso D'Escragnolle Taunay, São Paulo em Quatro Séculos (2v, 1953 e 1954), publicado sob os auspícios daquela Comissão; o Catálogo de Documentos Sobre a História de São Paulo existentes no Arquivo Ultramarino de Lisboa, publicado em 15 volumes entre 1956 e 1959 pelo Instituto Histórico e Geográfico Brasileiro ( $(\mathrm{HG} B$ ); bem como uma série de títulos lançados pelas Edições Melhoramentos, entre eles Isto é São Paulo! e São Paulo antigo, São Paulo moderno, devem ser compreendidos como parte desse esforço editorial em celebrar a cidade, que reunia promotores tanto públicos quanto privados.

Dessa espécie de boom editorial, destaco aqui o livro editado por José Olympio (1902-1990) em 1954, História e Tradições da cidade de São Paulo. Obra composta por três volumes escritos por Ernani da Silva Bruno (1 11 2-1986), ela consagrou "imagens" da cidade potentes até hoje - visíveis em expressões como "arraial de sertanistas" ou "burgo de estudantes" e ainda "metrópole do café", todas elas subtítulos dos volumes correspondentes aos períodos históricos analisados pelo autor $^{22}$. Esse triplo livro, que havia sido encomendado pelo próprio editor três anos 
antes com o objetivo explícito de ser uma "contribuição às comemorações do IV Centenário da fundação de São Paulo" 23 e que contava com desenhos inéditos de Candido Portinari (1903-1962) na abertura de cada volume, pretendia, segundo o próprio autor, dar conta da "longa e complexa história de São Paulo desde a sua fundação" até a data presente, num esforço para conseguir a "aproximação de dados esparsos - que andavam esquecidos ou perdidos por aí, [a fim de] enriquecer o conhecimento que se pode ter do passado da cidade e de sua personalidade"24. No longo prefácio que abre o primeiro volume do livro, Gilberto Freyre 11900 1987) reconhecia indiretamente Silva Bruno como herdeiro das suas próprias elucubrações sobre o passado, na medida em que aquele autor também se propusera a fazer uma análise do cotidiano da cidades. Em seguida, Freyre ressaltava o papel do estudo como "obra fundamental" não apenas para se conhecer o passado da cidade, mas para que "se firm[asse] ou se agu[çasse] no paulista metropolitano de hoje a consciência de responsabilidades de São Paulo para com o seu interior, com o Brasil e com a América, principalmente a chamada Latina" 25 . Nesse texto introdutório, o sociólogo pernambucano frisava a rara combinação de métodos empregados na narrativa de Silva Bruno:

do método biográfico ao histórico-sociológico; da indagação de fatos sociais de economia pelo método estatístico ao estudo de expressões folclóricas, aparentemente só pitorescas ou anedóticas mas na verdade socialmente expressivas da realidade ou do passado que se procura estudar e interpretar como um todo ou como um complexo ${ }^{26}$.

Tais características, que poderiam ser igualmente aplicadas ao livro de Morse, deviam garantir à obra de Silva Bruno um lugar de destaque na estante paulística. Entretanto, a despeito de ter sido publicada na importante Coleção Documentos Brasileiros - inaugurada em 1936 por Raízes do Brasil, livro de estreia de Sergio Buarque de Holanda (1902-1982) - e de ter contado com o prefácio do próprio organizador da coleção, a sua apreciação posterior parece tê-la relegado à categoria menor dos relatos memorialistas ${ }^{27}$. Lançados no mesmo ano e com pretensões de certo modo semelhantes - recontar a história de São Paulo desde a fundação aos dias presentes - as obras eram necessariamente distintas. Nos "Agradecimentos" da primeira edição do seu livro, Richard Morse destacava o caráter da sua "aventura" que ora se publicava e que, para ele, o distinguia dos demais: "antes um histórico crítico e interpretativo, do que um panegírico, como frequentemente as comemorações oficiais suscitam" 28 . Buscava deixar claro, de saída, o lugar institucional específico de onde falava, descolando-se das comemorações stricto sensu e pontuando suas almejadas interlocuções na Academia e a pretensão analítica que o guiava ${ }^{29}$.

A primeira apreciação pública sobre o livro que se tem notícia é a resenha publicada no Suplemento Literário do jornal O Estado de S. Paulo em 1956 por Florestan Fernandes (1920-1995), titular da cadeira de Sociologia 1 da Faculdade de Filosofia, Ciências e Letras da USP. No breve texto o sociólogo destacava "a perspectiva da 'síntese histórica' (...) engrandecida pela exploração
Brazil" (The Journal of Negro History, 1953).

19. Ver Richard Morse (1954).

20. As comemorações do IV Centenário mobilizariam os intelectuais paulistas sobremaneira, numa série de iniciativas para marcar a data e ressaltar o papel de São Paulo frente aos outros estados da federação. A "Exposição da História de São Paulo no quadro da História do Brasil", organizada pelo historiador Jaime Cortesão, com apoio de Mario Neme, Ernani da Silva Bruno, Helio Damante e Agostinho da Silva, e que em suas nove seções pretendia mostrar "os principais acontecimentos e vultos das várias fases da formação" do povo paulista, é um bom exemplo de como a história servia ali como legitimadora do presente; ver Exposição... (1954). Para uma análise ampla das comemorações, ver Sílvio Luiz Lofego (2004).

21. Para garantir uma identidade às obras, a coleção contava com uma capa única. Em 07/11/1952 o jornal $O$ Estado de $S$. Paulo, sob o título "Biblioteca do IV Centenário", já anunciava a publicação da tese de Morse (recém defendida) como o terceiro volume da série.

22. Ver Ernani da Silva Bruno (1954).

23. Cf. Ernani da Silva Bruno (1954, "Nota dos editores").

24. Cf. Ernani da Silva Bruno (1954, p.17).

25. Cf. Gilberto Freyre (1954, p.XI).

26. Cf. Gilberto Freyre (1954, p.XI).

27. Para uma análise do livro, e a discussão do sentido do memorialismo 
em Bruno, ver Sílvio Luiz Lofego (2001).

28. Cf. Richard Morse (1954, s/p.), grifo meu.

29. Mas mesmo sendo efetivamente lançada nas comemorações oficiais, essa edição, por problemas de ordem prática, acabou quase não circulando, sem chegar nem mesmo a ser distribuída comercialmente. Segundo Antonio Candido, tendo ficado num depósito que alagou, o livro não foi para as livrarias. Apenas alguns exemplares teriam sido oferecidos a conhecidos (cf. entrevista à autora em 16/03/2010). Na Nota explicativa da segunda edição brasileira, pode-se ler: "Este livro apareceu inicialmente em português, no ano de 1954, mas foi distribuído de maneira tão limitada, que a edição presente constitui de fato a sua primeira difusão pública no Brasil", cf. Richard Morse (1970, p.5).

30. Cf. Florestan Fernandes (1956, p.1).

31. Cf. Fernando Henrique Cardoso (1957, p.351).

32. Morse de fato apresenta os trabalhos da Escola Sociológica de Chicago, notadamente o trabalho de Robert Redfield sobre o México e a sua teoria do continnum folk-urbano, como sua principal interlocução teórica, tomando o cuidado, entretanto, de se afastar das injunções feitas a priori pelo colega norte-americano, que buscava estabelecer uma espécie de teoria sobre a penetração do mundo urbano nas comunidades rurais, a partir da análise de quatro comunidades mexicanas na década de 1930 e 1940, colocando à prova na própria pesquisa etnográfica as dicotomias téricas clássicas (comunidade e sociedade). Os resultados de Redfield contínua de recursos interpretativos fornecidos pelas ciências sociais", o que teria levado o autor a concentrar suas indagações nas análises dos "processos históricosociais, histórico-geográficos ou econômico-políticos e seus produtos dinâmicos". Florestan Fernandes concluía que a obra havia sido construída "sob preocupações historiográficas muito complexas", que revelavam a riqueza de suas investigações "tanto no plano empírico como no plano interpretativo", embora estivesse "longe" de considerá-la uma "obra-prima". Mesmo com essa ressalva, e altamente elogiosa em seu sentido geral, a resenha tem o mérito de captar as especificidades daquele trabalho no calor da hora de sua publicação e talvez tenha sido a única apreciação que tenha definido o livro como uma "história cultural"30. No ano seguinte, numa resenha na Revista Anhembi, o então jovem sociólogo Fernando Henrique Cardoso, orientando dileto de Florestan Fernandes, considerava aquele "um dos melhores trabalhos realizados sobre São Paulo, sendo sob muitos aspectos pioneiro na historiografia paulistana" - obra portanto que merecia "leitura cuidadosa"31. $\bigcirc$ sociólogo destacava como Morse, ao analisar as diversas esferas da existência, não elaborava "esquemas de interpretações causais" nem mesmo postulava "uma integração orgânica entre elas", o que, poderíamos acrescentar, o livrava de ser compreendido na chave determinista de outras obras sobre a cidade que pareciam ver na história colonial o destino manifesto da metrópole. Para Fernando Henrique, - trabalho ajudava inclusive a perceber certos desajustes da metrópole, devido justamente ao "seu ritmo desigual de crescimento e de transformação", ressaltando como o autor tivera o cuidado em explicitar que não partilhava das análises sociológicas "mais duras" que viam a metrópole como "desintegrativa", dando espaço a que novos valores - sociais e morais - pudessem ser reelaborados ${ }^{32}$. Com tudo isso, e levando em conta os objetivos a que Morse se propusera, Fernando Henrique Cardoso verificava que ele os havia cumprido "por vezes até de forma brilhante" 33 .

Pode-se supor por essas resenhas que a obra, ao menos no círculo intelectual composto pelos professores e alunos da Universidade de São Paulo, imediatamente encontrou leitores que o valorizaram. Luís Jackson, ao analisar o papel "extra-oficial" de Florestan Fernandes na condução da Anhembi, revista editada por Paulo Duarte (1 899-1984) que, sobretudo após 1954, passava a ter colaborações cada vez mais freqüentes daquele sociólogo e de seus assistentes como a resenha que Fernando Henrique publicou sobre Morse -, ajuda a precisar a importância desse texto crítico na trajetória posterior do livro. Tanto Anhembi como a Revista Brasiliense, situadas "a meio caminho entre os campos político e cultural", teriam servido para o debate científico "em decorrência sobretudo da atuação de Florestan Fernandes, que delas se utilizou como 'caixa de ressonância' para a legitimação de seu projeto acadêmico" ${ }^{34}$. Ainda que não seja o caso de desdobrar aqui os motivos da atuação de Florestan Fernandes na condução destas revistas, isso parece permitir afirmar, por exemplo, que o texto de Fernando Henrique não se tratava de uma resenha desinteressada do trabalho de um jovem estrangeiro sobre São Paulo feita por um sociólogo da USP em início de carreira, mas indício de uma 
certa concordância com a visão ali exposta da história da cidade, que valeria ser levada em conta por parte daqueles que estavam se tornando os criadores de uma "sociologia paulista" na universidade recém fundada ${ }^{35}$.

artigo que o próprio Florestan Fernandes escreveu como homenagem aos 70 anos de Morse, muitas décadas depois, não deixa mais dúvidas sobre o ponto, ao reconhecer a maestria com que um jovem historiador norte-americano se apropriara da história da cidade, construindo "uma das interpretações mais interessantes sobre o complexo desenvolvimento urbano" daquela metrópole, sobretudo no que dizia respeito ao seu passado ${ }^{36}$. Vale a pena recuperar um trecho mais longo desse novo comentário para precisar o argumento:

\begin{abstract}
O primeiro trabalho de envergadura do historiador não é, necessariamente, um item superficial em sua produção. Como explicar o passo ousado de partir do ponto zero da "colonização" lassinale-se: não da civilização, pois as terras eram ocupadas por diversas populações indígenas) e tentar percorrer os altos e baixos da transformação da "comunidade" em "metrópole"? Não basta para isso a energia juvenil. Carece o talento maduro, manejado pela imaginação histórica que agregue capacidade de invenção, dedicação extrema à exploração de fontes e de bibliografias exuberantes e confiança de que certas tendências gerais à continuidade e à mudança possuem fundamento in re. Desse ângulo, o historiador jovem ultrapassa a categoria de idade - a competência, a argúcia e o espírito criador ganham a primazia e decidem o que será a obra ${ }^{37}$.
\end{abstract}

E o que a obra foi? Como tento mostrar aqui, tornou-se a explicação por excelência dessa longa história da cidade. É certo que nesse caso se tratava de um artigo de homenagem e não de leitura feita no calor da hora, mas a escolha de Florestan Fernandes para tal homenagem ter recaído justamente sobre aquele "texto de juventude" não deve ser vista apenas como um elogio de ocasião ou a rememoração de um passado em comum de tempos já idos. Parece antes ser a reafirmação da importância de um trabalho que ele reputava pioneiro - ainda que surgido a partir de "alguns caminhos desbravados" - e que se constituiu como um primeiro "estudo da formação e desenvolvimento da cidade como totalidade histórica". Reconhecimento, portanto, do esforço precursor e totalizante que o norteamericano fizera para dar forma a uma longa e dispersa história, reunindo não apenas materiais difusos, mas buscando propor também uma compreensão interpretativa - esta sim a característica mais importante ali notada - dotando de sentido a vida urbana que se desenrolara em São Paulo durante os séculos ${ }^{38}$. Esforço que não teria sido feito por nenhum historiador local e que teria chegado a um resultado "mais que satisfatório" 39 . Porém, o intelectual paulista não se eximia, como a atividade de sociólogo militante requeria, de explicitar uma vez mais suas críticas e discordâncias - agora revistas com a distância do tempo - sobretudo em relação às análises de Morse sobre a metrópole contemporânea feitas naquela década de 1950. Tais análises, do seu ponto de vista, perdiam a capacidade crítica de julgamento visível em relação ao desenvolvimento histórico pregresso, em nome de um certo encantamento do autor norte-americano com a sua própria experiência na aparecem de forma mais acabada em seu livro The folk culture of Yucatán (1941), traduzido para o português poucos anos depois como Civilização $e$ Cultura de Folk: Estudo de variações culturais em Yucatan (1949).

33. Cf. Fernando Henrique Cardoso (1957, p.353). Vale notar que o sociólogo discordava apenas da "conotação valorativa de certas explanações”, que i m plicariam na impossibilidade de ver surgir "tipos diferentes de integração social em formas de vida urbana aparentemente caóticas" crítica que ele mesmo dizia não ser possível ampliar no reduzido espaço da resenha, mas que pareciam ter a ver com o capítulo final do trabalho no qual Morse lidava com a metrópole contemporânea e pensava alguns caminhos possíveis para a sua urbanização.

34. Cf. Luiz Jackson (2004, p.267).

35. A esse respeito, entre outros, ver Maria Arminda do Nascimento Arruda (2001, p. 189-330).

36. Cf. Florestan Fernandes (1995, p.89). Fernandes publica o texto "O Historiador Enquanto Jovem", que se detém sobre o livro de São Paulo publicado em 1954 e reeditado em 1970, no volume Culture and Ideology in the Americas: Essays in Honor of Richard M. Morse organizado por Dain Borges e Thomas Cohen (1995), ex-alunos de Morse, para a LusoBrazilian Review, por ocasião dos 70 anos do historiador.

37. Cf. Florestan Fernandes (1995, p.90).

38. Convém notar que o próprio Florestan Fernandes, juntamente com 
Roger Bastide, havia conduzido uma grande pesquisa para a UNESCO durante os anos de 1951 e 1952, sobre a situação dos negros na cidade de São Paulo e a sua incorporação na sociedade de classes, traçando um panorama desde os anos coloniais, que resultou no livro Relações raciais entre negros $e$ brancos em São Paulo (1955), dentro, portanto, do mesmo esforço totalizador da compreensão histórica que ele destacava como dado fundamental do trabalho de Morse.

39. Desde a fundação do Instituto Histórico e Geográfico de São Paulo (IHGSP) em 1895, compilações sobre o período colonial, em meio a ensaios de historiadores acadêmicos ou diletantes, buscavam construir a história de São Paulo nos seus primeiros séculos. Mas não se estendia essas visões ao presente da cidade, ainda que se as compreendessem como parte da explicação do mesmo. Memorialistas também recuperavam o passado, geralmente buscando fixar uma imagem da cidade que parecia desaparecer com o avanço implacável da urbanização. Ernani da Silva Bruno (1954), como se viu, parte de intenção semelhante a Morse e logra construir essa longa história, com um caráter, entretanto, de reunião de fatos, personagens e descrição de espaços da cidade que não se pretendem uma interpretação da mesma, ou talvez não tenha chegado a ser lida assim.

40. Ver Florestan Fernandes (1995).

41. Cf. Florestan Fernandes (1956).

42. Da edição em inglês de 1958, pude encontrar as resenhas de W. A. Tate (International Affairs, metrópole paulista naqueles anos ${ }^{40}$. $\bigcirc$ que na primeira resenha era visto de modo mais condescendente - como se nota quando afirmava que "a análise se beneficia do estado de espírito a que se refere ao dizer que São Paulo é a cidade que 'mais amo', sem perder a profundidade e o rigor indispensáveis em trabalhos desse gênero de investigações positivas" 41 -, era agora identificado como uma posição pouco aceitável para um trabalho de cunho científico.

Desde aquelas primeiras resenhas de Florestan Fernandes e de Fernando Henrique Cardoso o livro foi construindo uma discreta porém consistente fortuna crítica. Em 1958, seguindo o caminho mais ou menos comum das boas teses defendidas na academia norte-americana, saía a versão em inglês do livro pela Florida University Press, editora de uma universidade que tinha um programa de estudos latino-americanos já razoavelmente estruturado, sendo então publicado com o título From Community to Metropolis. A Biography of São Paulo. A edição levou a novas leituras e comentários ${ }^{42}$, entre os quais o do geógrafo francês e ex-professor da USP Pierre Monbeig (1908-1987), ele mesmo autor de importantes trabalhos sobre São Paulo lançados na mesma época que a primeira edição do livro de Morse ${ }^{43}$. Monbeig também foi profícuo em elogios, reconhecendo que não se tratava de apenas mais um item na já extensa bibliografia sobre São Paulo, mas de uma contribuição fundamental para a compreensão da cidade, e que o sucesso da empreitada era deste modo inquestionável. Se Fernandes acusaria adiante um ponto fraco do trabalho em relação à compreensão da metrópole contemporânea, Monbeig ressaltava a decisão acertada de se voltar ao passado mais remoto, para - século XVI mais precisamente, para a completa compreensão do papel contemporâneo da capital paulista - recuperando naquele passado ao menos uma característica para o entendimento da metrópole futura: a irradiação de sua influência e prestígio por sobre um vasto território regional desde o estabelecimento da vila jesuítica ${ }^{44}$ - característica de algum modo apontada pelo próprio geógrafo, aliás. Destacava ainda a maneira que o papel da São Paulo colonial era formulado pelo norte-americano, e quais as características ali recuperadas. Isso é compreensível não apenas pela concordância de visão de Monbeig, mas também porque na edição norte-americana tal período havia de fato ganhado maior destaque na estrutura do livro, passando a ter um peso maior na explicação da formação da metrópole. Deixando de ser apresentado em uma breve passagem na Introdução da obra, o período colonial ganhava uma análise mais detida, em um novo capítulo incorporado ao livro, no qual Morse dialogava com a bibliografia contemporânea sobre o tema bem como relacionava tal período com os desdobramentos posteriores da própria urbanização ${ }^{45}$.

Mas foi a segunda edição em português, publicada em 1970 sob um novo título, Formação histórica de São Paulo: de comunidade à metrópole, a que circulou mais amplamente, tornando-se a edição mais citada desde então. Nessa nova versão, além de republicar o capítulo Antecedentes ${ }^{46}$ e de escrever uma nova Introdução ${ }^{47}$, situando o livro nessa perspectiva temporal entre as duas edições brasileiras, o autor acrescentou um capítulo final, espécie de Epílogo que funcionava 
como uma atualização bibliográfica ${ }^{48}$ e que indiretamente dava conta do lugar de Morse na academia, não mais um recém doutor estudando uma capital latinoamericana, mas o professor de História da América Latina e chairmain do Latin American Studies Program da prestigiosa Universidade de Yale. O livro, republicado na coleção Corpo e Alma do Brasil dirigida pelo mesmo Fernando Henrique Cardoso, agora também ele um renomado sociólogo, foi editado ao lado de títulos que se tornaram referências no pensamento social brasileiro, como Brasil, terra de contrastes (1959) de Roger Bastide (1898-1974); Mudanças sociais no Brasil (1960) de Florestan Fernandes; A industrialização de São Paulo (1971) de Warren Dean (1932-1994); O modelo político brasileiro (1972) do próprio Fernando Henrique ou Raízes da concentração industrial em São Paulo (1977) de Wilson Cano. Pode-se sugerir assim que a mudança do título - de biografia para formação - buscava explicitar os laços daquela obra com a tradição do pensamento social brasileiro representada na coleção, e, de novo, reafirmava por parte do editor a leitura da obra como uma contribuição ao entendimento da própria sociedade brasileira (paulista, ao menos). Convém lembrar de toda a tradição do pensamento social que se funda no Brasil sob a ideia da "formação", vista quase sempre como incompleta e devedora do passado colonial lque ora deve ser descartado, ora retomado, para que a formação possa finalmente se completar). A mudança de título tinha portanto a vantagem de explicitar diretamente a filiação intelectual do autor, ou ao menos, a identificação da obra com um certo modo de entender o país que, sem desvinculá-lo de uma "tradição", defendia uma perspectiva local49.

Nota-se assim que ao longo de todos esses anos, de modo oblíquo, sem muito alarde nem repercussões polêmicas ${ }^{50}$, o trabalho de Morse sobre São Paulo foi sendo consagrado por meio de cada uma dessas leituras, ocupando cada vez mais o lugar de obra explicativa da história do excepcional crescimento da capital paulista. Se para o próprio historiador o livro acabou sendo uma plataforma para um programa de estudos, ao ver em São Paulo um exemplo de desenvolvimento para a cidade latino-americana - perspectiva que se afirma sobretudo na edição de 1970, quando Morse deixa de ver a cidade como exceção e a afirma como a "cidade latino-americana" por excelência - essa leitura entretanto parece não ter dado frutos por aqui. Tampouco o fato de ter buscado na cultura uma chave de compreensão do passado foi devidamente valorizado ou sublinhado ${ }^{51}$. No geral, tais apostas não parecem ter sido levadas a sério pelos seus leitores, pois não se nota desdobramentos das hipóteses de Morse acerca do lugar de São Paulo na América Latina nem dos métodos interpretativos a partir da cultura, pelo menos até a renovação historiográfica que chega ao Brasil nos anos 1980 - e que passa a incluir a literatura de forma mais frequente nos estudos urbanos -, mas, com certeza, bebendo em outras fontes ${ }^{52}$.

Passado mais de meio século de sua publicação, o que há é uma espécie de naturalização da história que Richard Morse apresentou sobre a evolução urbana de São Paulo. O trabalho da socióloga Maria Arminda do Nascimento Arruda sobre a capital paulista na década de 1950 é, nesse sentido, paradigmático ${ }^{53}$. Tomando
1959); Calvin Billman (The Americas, 1959) e Pierre Monbeig (The Hispanic American Historical Review, 1960).

43. Monbeig é autor de Pionniers et planteurs de São Paulo (1952), resultado de sua tese de doutorado defendida na Sorbonne em 1950 e La Croissance de la Ville de São Paulo (1953), além de outros títulos sobre o Brasil. Em La Croissance o geógrafo também faz um grande histórico do crescimento urbano da cidade desde a sua fundação, focalizando os aspectos sócio-geográficos da transformação da cidade e da região.

44. Ver Pierre Monbeig (1960).

45. Ver Richard Morse (1958, p. 2-19). Enquanto na edição de 1954 e também na tese de 1952 a história colonial era "resumida" em poucas páginas na introdução - ainda que o primeiro capítulo, Colonialismo e novos estimulantes (cf. Richard Morse, 1954, pp.19-32), justamente mostrasse como os humores coloniais permaneciam inalterados mesmo nas vésperas da Independência -, o novo capítulo inserido na versão em inglês, Antecedents, num certo sentido retomava questões já exploradas no mestrado também apresentado em Columbia (ver Richard Morse, 1947), mesclando a bibliografia anteriormente utilizada com títulos que começavam a renovar a tradição historiográfica colonial paulista, entre os quais os trabalhos sobre São Paulo de Sergio Buarque de Holanda. Morse também discutiria com uma bibliografia atualizada sobre as cidades coloniais portuguesas e espanholas no Novo Mundo, inserindo a experiência paulista num contexto maior da 
urbanização colonial americana.

46. Cf. Richard Morse (1970, p.7-24).

47. Cf. Richard Morse (1970, p.27-38).

48. Intitulado "Ecologia, Sociedade, Cultura: reconsideração de alguns temas (1968)" (cf. Richard Morse, 1970, pp.379-417), essa atualização era fundamental, na medida em que neste arco temporal 1950-1970 - uma importante produção sobre a cidade latino-americana havia aparecido. A esse respeito, ver Adrián Gorelik (2008).

49. Para uma discussão aprofundada sobre o conceito de formação por meio da análise da obra de três intelectuais brasileiros (Antonio Candido, Gilda de Mello e Souza e Lucio Costa), ver Paulo Arantes e Otília Arantes, (1997).

50. Como seria o caso do livro O espelho de Próspero: cultura e ideias na América, lançado em 1988, sem dúvida o trabalho mais conhecido deste autor no Brasil, muito por conta das teses polêmicas que defende.

51. À exceção, como vimos, da sofisticada resenha de Florestan Fernandes em 1956, que captava as discussões do livro não deixando de ressaltar a importância dada por Morse à "cidade letrada".

52. A esse respeito, ver Ronaldo Vainfas (1997, p.127-162) e para o campo específico da história urbana, mas dedicando pouco espaço ao Brasil, ver Ronald Raminelli (1997, p.185-202). Penso aqui em livros como o de Flora Süssekind, As Revistas de Ano e a invenção do Rio de Janeiro (1986) ou de Nicolau Sevcenko, Orfeu o IV Centenário como um evento condensador da experiência de metropolização vivida naqueles anos, e tendo na perspectiva cultural a chave de entendimento da metrópole, em seu livro Metrópole e cultura: São Paulo no meio-século, a socióloga se vale do trabalho de Morse como fonte para comprovar seus argumentos, sem jamais encarar o mesmo como um documento, a despeito do livro ter sido lançado inicialmente pela Comissão do IV Centenário e do fato da autora discutir e analisar brevemente essas publicações ${ }^{54}$. Além disso, a perspectiva cultural que está explicitamente presente no trabalho de Morse como forma de compreensão da cidade em nenhum momento é ressaltada pela socióloga, ainda que certamente ela tome dali alguns insights, pois seu trabalho pretende justamente formular a identidade "cultural" da metrópole 55 .

Esse exemplo poderia ser desdobrado em outros, mas minha intenção aqui é apenas reforçar como a obra de Morse vem sendo tomada como fonte obrigatória da história da cidade, notando que se pouco se discutiu de seu conteúdo, menos ainda se tratou de sua forma, o que acaba por nublar afinal porque o livro tem importância. O norte-americano se aproveitou de um material existente e muitas vezes já explorado pelos memorialistas, entretanto, não buscava fazer uma crônica da cidade. Sua compreensão da evolução urbana passava pela análise dos ciclos ou etapas da história da cidade que se sucediam, mas mostrava que tais períodos também se sobrepunham, complexificando a estrutura social e urbana a cada novo movimento e descartando o puro avanço cronológico ou natural que se pode encontrar naquelas crônicas ou memórias ${ }^{56}$. A periodização da história da cidade em fases - opção tomada por quase todos os autores que buscaram compreender a evolução urbana daquela cidade, de Ernani da Silva Bruno a Pierre Monbeig, de Luís Saia (191 1-1975) a Benedito Lima de Toledo -, na sua formulação tem uma distinção importante. Em sua obra, Morse se apoiou em movimentos literários, destacando o papel do Romantismo e do Modernismo como pólos importantes que funcionavam como uma espécie de condensadores da experiência urbana de cada período ${ }^{57}$. Com isso, dava um sentido forte àqueles momentos - simbolizados na fundação da Faculdade de Direito e na Semana de 1922 ou nas figuras de Álvares de Azevedo (1 83 1-1852) e de Mario de Andrade (1 893-1945) -, pouco antes e pouco depois do auge da economia cafeeira, que sói ser lida como "a" explicação do desenvolvimento urbano de São Paulo, pontuando a perspectiva literária lou culturall) que animava seu trabalho. Os literatos seriam ali uma espécie de "leitores privilegiados" da cidade, "com habilitações culturais, profissionais e estéticas que os dotam de um olhar refinado, sensível e arguto", na formulação precisa de Sandra Pesavento ${ }^{58}$. Morse se valeu da literatura como acesso privilegiado ao passado para compreender o ethos paulista, relativizando desse modo a importância das injunções econômicas que mais comumente servem para explicar as transformações sociais e urbanas da capital. Por isso, talvez, seja possível reconhecer em seu texto um sabor das abordagens memorialísticas, ou ainda a liberdade de uma tradição ensaística menos afeita às rígidas formas acadêmicas, mesmo que se tratasse originalmente de um texto escrito para a Academia. Tal opção certamente não foi inconsciente. 
Num artigo publicado em 1949, ainda durante a redação da sua tese, Morse, ao definir o papel do historiador, reconhecia a necessidade de recuperar a narrativa, que talvez tivesse ficado menosprezada ante os desejos de cientificidade dos historiadores contemporâneos:

O historiador, pois, deve encontrar novas técnicas de expressão que não prejudiquem sua função de narrador dos feitos da humanidade. Seu caso é o mesmo do poeta, do novelista e do dramaturgo, quando o épico, a novela picaresca e a tragédia clássica deixaram de ser formas literárias possíveis. Como eles, o historiador deve encontrar uma nova forma de expressão ${ }^{59}$

Essa, parece-me, é a força maior do trabalho de Richard Morse sobre São Paulo: conteúdo e forma que se alimentam mutuamente. Sem abrir mão de uma perspectiva totalizante, Morse não cedia às generalizações e simplificações. Sem menosprezar o rigor da pesquisa, não desprezava a boa escrita. Além disso, na periodização do processo histórico vivido pela cidade, se marcava cortes e rupturas, também mostrava continuidades e adaptações, ressaltando as indecisões ou mesmo indefinições que ali se viveu. A cidade, porém, era compreendida em relação ao quadro mais amplo da história do Brasil, como uma unidade que não podia ser fracionada em sua verdadeira essência - e esse seu esforço maior. Sem descuidar do rigor que uma obra escrita inicialmente como tese de doutorado pressupunha ter, sua pretensão foi dialogar com os trabalhos que buscavam entender o Brasil.

Em sua trajetória, desde esse primeiro trabalho de maior fôlego, Morse se aproximou muitas outras vezes da história urbana, produzindo reflexões que sem dúvida enriquecem a compreensão dessa história na América Latina. Trabalhos que buscaram ampliar a forma de compreensão das cidades, extrapolando a história material - compreendida pelos estudos de arquitetura e urbanismo -, ao tomar as cidades como este artefato complexo "que reflete fielmente as condições nas quais foi criado, mas que tem a capacidade de impor efeitos - formas de vida e mentalidades - muito mais duradouros que essas mesmas condições" 60 . Realidade complexa e dinâmica, as cidades estudadas por Morse ganharam inteligibilidade por serem consideradas nestas múltiplas dimensões: como artefato construído, mas também como campo de forças e campo de significações ${ }^{61}$. Distanciando-se das leituras que viam a realidade material como reflexo ou consequência das transformações econômicas, Morse demonstrou desde seu primeiro trabalho sobre São Paulo que a cultura - e a literatura em especial - tinha muito a dizer sobre o passado, da cidade e da sociedade.

Mas talvez seja a partir de seus anos em Yale que se pode perceber mais claramente como essa forma de compreensão do fenômeno urbano se afirma. Foram sobre a história das cidades a maioria de seus cursos no Departamento de História daquela universidade - Study of the City; Introduction to the Study of the City; Latin American Urban History; Urban History of Colonial Latin American; Urban History and Colonial Latin American Studies; Studies in Latin American Urban History - e em todos sua intenção pareceu ser a de mesclar aos autores mais propriamente extático na metrópole (1992), como exemplos dos trabalhos que propunham pensar as cidades partindo da literatura ou da cultura em geral. Autores como Gorelik e Almandoz, entretanto, mostram haver uma continuidade da perspectiva de Morse sobre as cidades latino-americanas em José Luis Romero e Angel Rama, ainda que Almandoz afirme que é apenas na década de 1980 que se pode realmente perceber a incorporação efetiva da literatura como fonte nos estudos históricos urbanos (ver Adrián Gorelik, 2004; Arturo Almandoz, 2002). Mas se pode lembrar aqui de Rezende de Carvalho em $O$ Rio de Janeiro por seus autores, que tem nomeadamente no trabalho de Morse uma referência para pensar o Rio de Janeiro (ver Maria Alice Rezende de Carvalho, 1994, p.15-63).

53. Ver Maria Arminda do Nascimento Arruda (2001).

54. Inspirando-se declara -damente em Viena fim-deséculo de Carl Schorske, o livro propõe um retrato polifônico da capital paulista em 1950, dedicando os capítulos a distintas manifestações culturais da e na cidade, como o teatro de Jorge Andrade, a sociologia de Florestan Fernandes, as vanguardas concretas e os museus de arte. $\mathrm{O}$ primeiro capítulo Tempos, lugares, sociabilidades funciona como uma espécie de "apresentação" da cidade naquela década, focalizando mais detidamente as comemorações do IV Centenário (2001, p. 49133).

55. Uma cidade, como a socióloga destaca, que viveu naqueles anos de 1950 o nascimento dos museus de arte (como o MAM e o MASP); a criação da Bienal de Arte e de Arquitetura; um boom teatral que incluía do 
Teatro Brasileiro de Comédia ao Teatro Oficina, passando pela criação da EAD; que constituiu uma empresa cinematográfica que pretendia rivalizar com Hollywood (a Cia. Cinematográfica Vera Cruz); e que, na Universidade de São Paulo, via os primeiros alunos ocuparem agora os postos de professores universitários, responsáveis pela criação de um pensamento científico autônomo; ver Maria Arminda do Nascimento Arruda (2001).

56. Ver Ana Claúdia Fonseca Brefe (1993); Pode-se lembrar dos livros de Antonio Egydio Martins, São Paulo antigo 1554-1910 (2v., 1911); Affonso Antonio de Freitas, Tradições $e$ reminiscências paulistanas (1921); Paulo Cursino de Moura, São Paulo de outrora: evocações da metrópole (1932); Maria Paes de Barros, No tempo de dantes (1946); Amadeu Amaral, Tradições populares (1948), o já citado Ernani da Silva Bruno, Histórias $e$ tradições da cidade de São Paulo (1954) e o posterior Oscar Americano, São Paulo naquele tempo, 1895-1915 (1957) - em que se nota, já nos títulos, o desejo de recuperar um tempo perdido: "antigo", "reminiscências", "dantes", "tradições", "histórias", "naquele tempo", distintos da vontade mais analítica expressa na expressão "de comunidade à metrópole" $\mathrm{e}$ que "formação histórica de São Paulo" não deixa dúvidas. Portanto, o ponto de fuga do livro é o presente.

57. Vale notar, operação feita contemporaneamente ao artigo de Antonio Candido A literatura na evolução de uma comunidade publicado no suplemento especial do jornal O Estado de S. Paulo para as comemorações do IV Centenário, autor com o preocupados com a urbanização, outros que pudessem contribuir com aportes distintos: poetas, escritores e ensaístas ${ }^{62}$. Além disso, o historiador participou ativamente dos congressos, seminários, encontros e programas que tinham a história urbana como tema, editando com o argentino Jorge Enrique Hardoy e o norteamericano Richard Schaedell, já na década de 1970, obras que além de contribuirem para essa forma de compreensão da história das cidades na América Latina, foram fundamentais para a própria constituição de um campo de história urbana, entre as quais: La investigación urbana latinoamericana: tendencias y planteos (1971); The Urban Development of Latin America 1750-1920 (1971); Las ciudades latinoamericanas (1 973); Ensayos histórico-sociales sobre la urbanización en America Latina (1978), com Hardoy e Schaedel; e em fins dos anos 1980, Nuevas perspectivas en los estudios sobre historia urbana de Latinoamerica (1989), co-organizado com Hardoy ${ }^{63}$.

Mas se reconhecemos que Morse construiu uma trajetória que tem interesse para esse campo disciplinar, a história urbana, voltamos à pergunta inicial: o que faz daquele primeiro livro sobre São Paulo um "clássico"? Clássico em que sentido? Por ser citado em nove entre dez trabalhos sobre a cidade? Ou por propor caminhos interpretativos para a compreensão da metrópole - que eventualmente ultrapassam a própria história urbana - pretendendo de fato contribuir para o pensamento social? Richard Morse analisou a história de uma cidade latinoamericana, afirmando que a despeito de seu ethos ibérico e católico ela se transformava em metrópole industrial capitalista. Para compreender como isso se deu, voltou-se para a própria transformação do ethos paulista, que ele pode compreender ao considerar a cultura urbana de São Paulo. $\bigcirc$ que nos anos 1950 parecia ser anunciado em seu livro em alguns momentos, mas talvez de forma ambígua ou imprecisa, em 1970 se afirmava e se ampliava. Nessa reedição, Morse buscou deixar claro a importância do ethos ibérico e católico como forma de resistir a um desenvolvimento capitalista, cujo traçado parecia definido para os países periféricos. Com isso, Morse reinseria a história da capital paulista numa larga tradição ibérica, valorizando tal "herança" e descolando-a da leitura de uma São Paulo yankee. Ou, dito de outra forma, o intelectual insistia na necessidade de entender a cidade como parte de uma tradição específica para verdadeiramente compreendê-la como metrópole industrial, ainda que, insisto, na sua especificidade latino-americana.

Contudo, ao que parece, foi menos por ter proposto uma abordagem que buscava unir esse ethos ao próprio desenvolvimento capitalista - minimizando as possíveis incompatibilidades e preocupado em evidenciar uma possível interação entre ambos -, que por ter sido lido e comentado por nomes fundamentais do campo intelectual paulista, que Morse garantiu ao seu livro um lugar na historiografia. Um lugar hoje tão "natural" que já nem se percebe qual a história ali contada, menos ainda sua possível potência como forma de compreensão da cidade. 


\section{REFERÊNCIAS}

\section{FONTES}

Yale University / Manuscripts \& Archives Library, New Haven - Richard McGee Morse Papers/ Serie III. Yale University, 1964-1977.

\section{LIVROS, ARTIGOS E TESES}

ALMANDOZ, Arturo. Notas sobre historia cultural urbana: una perspectiva latino-americana. Perspectivas urbanas/Urban Perspectives, Barcelona n. 1, p. 29-39, 2002. Disponível em $<$ http://www.etsav.upc.es/urbpersp/num01/art01-3.pdf>. Acesso em 15/05/2012.

ALMEIDA, Paulo Roberto. Os estudos sobre o Brasil nos Estados Unidos: a produção brasilianista no pós-Segunda Guerra. Estudos Históricos, Rio de Janeiro, n. 27, p. 31-61, 2001. Disponível em <bibliotecadigital.fgv.br/ojs/index.php/reh/article/download/2138/1277>. Acesso em 23/08/2011.

ARANTES, Paulo; ARANTES, Otília. Sentido da formação. Três estudos sobre Antonio Candido, Gilda de Mello e Souza e Lucio Costa. Rio de Janeiro: Paz e Terra, 1997.

ARRUDA, Maria Arminda do Nascimento. Metrópole e Cultura. São Paulo no meio século XX. Bauru: Edusc, 2001

BREFE, Ana Cláudia Fonseca. A cidade inventada: a Paulicéia construída nos relatos dos memorialistas. Dissertação (Mestrado). Instituto de Filosofia e Ciências Humanas da Unicamp, Campinas, 1993.

BIBLIOTECA do IV Centenário. O Estado de S. Paulo. 07/11/1952, p. 10. Disponível em: $<$ http://acervo.estadao.com.br/pagina/\#!/19521107-23771-nac-0010-999-10-not/busca / Ri\%C3\%A7hard+Morse>. Acesso em 30/05/2012

BLAJ, Ilana. A trama das tensões - o processo de mercantilização de São Paulo colonial (16811721). São Paulo: Humanitas, 2002.

BRUNO, Ernani da Silva. História e tradições da cidade de São Paulo, 3 v.. Rio de Janeiro: José Olympio, 1954.

CANDIDO, Antonio. Young Mr. Morse. In: BOMENY, Helena (org.). Um americano intranquilo. Rio de Janeiro: Ed. FGV, 1992. p. 7-12.

CARDOSO, Fernando Henrique. Livros. Revista Anbembi, São Paulo, v. 26, n. 76, p.351-353, 1957.

CARVAlHO, Maria Alice Rezende de. Quatro vezes cidade. Rio de Janeiro: Sette Letras, 1994.

CASTRO, Ana Claudia Veiga de. Um americano na metrópole [latino-americana]. Richard Morse e a bistória cultural urbana de São Paulo, 1947-1970. Tese (doutorado), Universidade de São Paulo / Faculdade de Arquitetura e Urbanismo, São Paulo, 2013.

EXPOSIÇÃO da História de São Paulo no quadro da História do Brasil - Guia para o Visitante. São Paulo: Comissão do IV Centenário de São Paulo, 1954. qual Morse dialogava na formulação de suas hipóteses; ver Antonio Candido, (1998 [1954], p.139-68).

58. Ver Sandra Jatahi Pesavento (1995, p.284).

59. Cf. Richard Morse (1949, p.36).

60. Cf. Adrián Gorelik (2009, p.16)

61. Ver Ulpiano Bezerra de Meneses (1996).

62. Em Yale, Morse ofereceu também cursos sobre História da América Latina, História do Brasil e Modernismo brasileiro, mas em menos oportunidades. Cf. Serie III. Yale University, 1964-1977, Richard McGee Papers, Manuscripts and Archive Librart, Yale University.

63. Bem como uma série de artigos escritos sobre o tema e publicados ao longo de sua carreira. 
FERNANDES, Florestan. Resenha Bibliográfica: De comunidade à metrópole. O Estado de $S$. Paulo, 20/10/1956, Suplemento Literário, p.1. Disponível em <http://acervo.estadao.com.br/ pagina/\#!/19561020-24991-nac-0010-lit-2-not>. Acesso em 30/05/2012.

O Historiador enquanto jovem. BORGES, Dain; COHEN, Thomas. Luso-Brazilian Review, Madison, v. 32, n. 2 [Culture and Ideology in the Americas: Essays in Honor of Richard M. Morse], p. 89-92, winter, 1995.

GORELIK, Adrián. Richard Morse y la "ciudad latinoamericana": apogeo y decadencia de un ciclo. Relea; Revista Latinoamericana de Estudios Avanzados, Caracas, n. 20, p. 25-54, jul.dez., 2004.

La aldea en la ciudad. Ecos urbanos de un debate antropologico. Revista de Antropología, Córdoba, n.1, p. 73-96, out., 2008.

Cultura urbana latinoamericana: un canon y sus destiempos. Brújula, Davis (CA), v.5 [Ciudades latinoamericanas], p. 9-30, 2007. Disponível em <http://hia.ucdavis.edu/ brujula/Current\%20Issue.htm>. Acesso em 10/02/2009.

. José Luis Romero: el historiador y la ciudad. In: ROMERO, José Luis. La ciudad occidental: culturas urbanas en Europa y América. Buenos Aires: Siglo XXI, 2009. p. 15-46.

JACKSON, Luiz A sociologia paulista nas revistas especializadas (1940-1965). Tempo social, São Paulo, v.16, n.1, pp.263-283, jan.-jun., 2004. Disponível em <http://www.scielo.br/ scielo.php?script=sci_arttext\&pid=S010320702004000100013>. Acesso em 20/03/2012.

KUJAWSKI, Gilberto de Mello. A ironia como método de análise. O Estado de S. Paulo, São Paulo, 14/05/1988, p. 10.

LOFEGO, Sílvio. Luís. Memória de uma metrópole: São Paulo na obra de Ernani da Silva Bruno, São Paulo: Annablume, 2001.

IV Centenário da Cidade de São Paulo: entre o passado e o futuro. São Paulo: Annablume, 2004.

MARINS, Paulo César Garcez. Um lugar para as elites: os Campos Elísios de Glette e Nothmann no imaginário urbano de São Paulo. In: LANNA, Ana Lúcia Duarte et al. (org.) São Paulo, os estrangeiros e a construção das cidades. São Paulo: Alameda, 2011. p. 209-44.

MEHY, José Carlos Sebe Bom. A colônia brasilianista (História oral de vida acadêmica). São Paulo: Nova Stella, 1990.

MENESES, Ulpiano Bezerra de. Morfologia das cidades brasileiras: introdução ao estudo histórico da iconografia urbana. Revista USP, São Paulo, n. 30, jun.-ago., p. 145-155, 1996.

MONBEIG, Pierre. La croissance de la ville de Sao Paulo. Grenoble: Institut et Revue de Géographie Alpine, 1953.

Book Review: From Community to Metropolis. The Hispanic American Historical Review, Durham (NC), v. 40, n. 1, p. 120-122, fev., 1960.

MORSE, Richard. São Paulo: The Early Years. Dissertação (mestrado). Columbia University / Faculty of Political Science, Nova York, 1947.

O pesquisador social e o historiador moderno. Revista do Arquivo Municipal, São Paulo, n. 113, p.36-52, 1949. 
São Paulo. City under the Empire (1822-1889). Tese (doutorado), Columbia Universtity / Faculty of Political Sciences, Nova York, 1952.

De comunidade a metrópole: a biografia de São Paulo. Tradução M. Aparecida Madeira Keberg. São Paulo: Comissão do IV Centenário, 1954.

From community to metropolis: biography of Sao Paulo, Brazil. Gainsville: University of California Press, 1958.

Formação bistórica de São Paulo: de comunidade a metrópole. Tradução dos acréscimos Antonio Candido e Maria Sylvia Carvalho Moreira. São Paulo: Difel, 1970.

MOTA, Carlos Guilherme. Um americano intranquilo. In: BOMENY, Helena (org.). Um americano intranquilo. Rio de Janeiro: Ed. FGV, 1992. pp.13-20.

PASSOS, Maria Lúcia Perrone (org.). Os campos do conhecimento e o conhecimento da cidade. São Paulo: Museu Paulista da USP, 1992. (Cadernos de História de São Paulo, n.1).

PESAVENTO, Sandra Jatahi. Muito além do espaço: por uma história cultural do urbano. Estudos Históricos, Rio de Janeiro, n. 16, p.279-290, 1995. Disponível em <http:// bibliotecadigital.fgv.br/ojs/index.php/reh/article/viewArticle/2008>. Acesso em 03/04/2012.

RAMINELLI, Ronald. História cultural urbana. In: CARDOSO, Ciro Flamarion; VAINFAS, Ronaldo (org.). Domínios da História: ensaios de teoria e método. Rio de Janeiro: Elsevier, 1997. p.185-202.

REIS FILHO, Nestor Goulart. O campo da arquitetura e do urbanismo. In: PASSOS, Maria Lúcia Perrone. (org.),:Os campos do conhecimento e o conhecimento da cidade. São Paulo: Museu Paulista da USP, 1992. p.37-44. (Cadernos de História de São Paulo, n. 1).

TORRÃO FILHO, Amílcar. Paradigma do caos ou cidade da conversão? São Paulo na administração do Morgado de Mateus. São Paulo: Annablume, 2010.

TENÓRIO [TRILLO], Mauricio. Profissão: Latin Americanist: Richard Morse e a historiografia norte-americana da América Latina. Estudos Históricos, Rio de Janeiro, v. 2, n. 3, p. 102132 1989. Disponível em <http://bibliotecadigital.fgv.br/ojs/index.php/reh/article/ view/2279/1418>. Acesso em 12/02/2009.

VAINFAS, Ronaldo. História das mentalidades e história cultural. In: CARDOSO, Ciro Flamarion; VAINFAS, Ronaldo. (org.). Domínios da História: ensaios de teoria e método. Rio de Janeiro: Elsevier, 1997. p. 127-62.

Artigo apresentado em 27/08/2012. Aprovado em 19/12/2013. 